\title{
A unidade originária da percepção e da linguagem em Jan Patočka
}

\author{
Renaud Barbaras \\ Paris-1 Panthéon-Sorbonne
}

\begin{abstract}
resumo Neste artigo exploramos algumas indicações, presentes nos textos de Patočka, que apontam para uma concepção da linguagem que não a põe mais como camada derivada com relação a um solo perceptivo originário. Dissociando intuitividade e originariedade, Patočka estabelece uma co-originariedade entre linguagem e percepção, co-originariedade da qual procuramos ao mesmo tempo esclarecer o sentido e determinar os limites.
\end{abstract}

palavras-chave linguagem - percepção - fenomenologia - intuição - fala

Em virtude do "princípio dos princípios" husserliano que requer que a intuição doadora originária seja a fonte legítima para o conhecimento, a linguagem geralmente aparece, na tradição fenomenológica pós-husserliana, como um estrato decerto essencial, mas derivado, na medida em que remete necessariamente à camada mais profunda da percepção. A questão da relação da linguagem com a percepção é, portanto, a questão das modalidades de dependência e de derivação da esfera lingüística com respeito ao campo perceptivo originário. Tal é igualmente a posição de Patočka no único texto substancial que consagra à linguagem, a saber, na última parte da tese de 1936 (publicada em francês em 1976) O mundo natural como problema filosófico. No entanto, no posfácio que acrescenta à tradução francesa de 1976, Patočka oferece uma indicação que parece nos encaminhar para uma direção inteiramente diferente. Após ter caracterizado o mundo natural como "aquele que o ser humano traz consigo, em razão de sua estrutura ontológica, enquanto esse ser-com cuja fundação Recebido em 15 de dezembro de 2005. Aceito em 31 de janeiro de2006. Tradução de Bento Prado Neto.

doispontos, Curitiba, São Carlos, vol. 3, n. 1, p.63-81, abril, 2006 
última deve ser encontrada na temporalidade ou, mais exatamente, nas duas possibilidades de temporalização que são o projeto de si em meio às coisas e o recolhimento nos limites mesmos do humano", Patočka acrescenta: "Retomando o problema desse modo, colocamo-nos em condições de operar a revisão daquele modo antigo de conceber a linguagem segundo o qual esta seria um fenômeno não desprovido de fundamento, sem dúvida, mas que repousaria sobre uma camada mais profunda, a do perceptivo. A teoria husserliana de uma matéria hylética que receberia sua forma da intenção é maculada por um sensualismo latente; cabe substituí-la por uma concepção na qual a linguagem esteja indissoluvelmente ligada aos próprios fundamentos do ser humano, à sua compreensão de ser" (PATOČKA, 1976, p. 178). Reencontramos essa tese enigmática sob uma forma um pouco mais desenvolvida em outra versão, redigida em francês, desse posfácio: “a linguagem não é de modo algum um patamar superior de nossa vida no mundo em meio às coisas, que teria por nível elementar o da percepção. A linguagem, em sua possibilidade profunda, é condição de possibilidade da própria percepção humana. O campo primário do mundo é o da linguagem. Os comportamentos abertos, que sempre constituem um modo de desvelamento, desdobram-se sobre o fundamento daquilo que poderíamos chamar de linguagem originária. O que equivale a dizer que, no homem, a origem da linguagem é anterior à fala, que a linguagem não poderia, portanto, ser compreendida unicamente no nível da fala. Só assim poderemos evitar o sensualismo latente que se observa em certos fenomenólogos" (PATOčKA, 1995, p. 140). Tais textos impressionam por sua radicalidade. Não apenas a linguagem não deve mais ser pensada como um estrato derivado remetendo à percepção, mas, na qualidade de linguagem originária que deve ser distinguida da fala, deve ser concebida como o que está no próprio fundamento da percepção. Longe de a linguagem derivar da percepção, é na linguagem que a percepção encontra sua possibilidade mais profunda. É de se esperar que tal afirmação não venha sem uma reformulação radical dos conceitos de linguagem e de percepção, reformulação de que Patočka nos dá pelo menos uma idéia negativa quando faz a concepção clássica da linguagem, como camada subordinada, tributária de uma versão sensualista da percepção que atribui a Husserl, mas também a outros fenomenólogos (Merleau-Ponty?). Muito embora não dispo- 
nhamos de nenhum texto sobre a linguagem que permita esclarecer diretamente essas afirmações enigmáticas, uma leitura atenta dos textos fenomenológicos fundamentais de Patočka deveria não obstante permitir atribuir-lhes um sentido. É o que nos propomos fazer aqui. No entanto, só será possível justificar a tese de uma fundação da percepção numa linguagem originária após ter rechaçado a fundação da linguagem na percepção, o que exige primeiro evidenciar a co-originariedade, fundada na própria essência da fenomenalidade, entre a percepção e a linguagem compreendida como fala.

A perspectiva própria a Patočka encontra sua fonte numa discussão crítica das teses fundamentais da fenomenologia de Husserl. A inflexão à qual as submete justifica-se, nas suas próprias palavras, pelo sensualismo latente que contêm; mas esse sensualismo é a conseqüência de um subjetivismo que corresponde, ele próprio, a uma compreensão errônea da estrutura da doação intuitiva como preenchimento de uma visada no vazio. Patočka credita a Husserl a "grande descoberta dos modos de doação, notadamente do modo da originariedade que leva ao desvelamento da relação estrutural, talvez efetivamente universal, entre a visada no vazio e o preenchimento" (PATOčKA, 1988, p. 243). Na primeira Investigação lógica, essa estrutura é evidenciada a partir de uma análise da expressão lingüística, cuja função de significação é distinguida da função de manifestação em virtude do duplo sentido que pode ser conferido ao signo (indicial, significante). Essa análise conduz à distinção cardinal entre os atos que conferem sentido, ou intenções de significação, e os atos que preenchem o sentido, atos que realizam a relação da expressão com sua objetidade e delimitam o campo daquilo que Husserl chamará intuição. Ora, na medida em que essa distinção entre os dois tipos de atos provém de uma análise da linguagem, marcar a importância dessa distinção para a própria fenomenologia, como o faz Patočka, é sublinhar o quanto, em Husserl, esta última deve ao fenômeno da linguagem. Ainda que a linguagem apareça como um estrato derivado da camada perceptiva originária, o fato é que o fenômeno da linguagem conforma profundamente a própria análise da percepção: "é quando se aprendeu pelo viés da dinâmica da significação lingüística na articulação entre intenção vazia e preenchimento que podemos notar que mesmo a percepção de um objeto sensível implica o vazio e o pleno (...). Portanto, a intuição vazia e seu 
preenchimento não são apenas fenômenos originários da linguagem, mas um fenômeno da consciência em geral: uma prova de seu caráter sintético. Mas, sem o fenômeno fundamental da linguagem, nunca poderíamos ter descoberto esse caráter sintético: a linguagem descobre o verdadeiro caráter da intuição, a saber, o fato de que repousa essencialmente em intenções vazias não intuitivas" (PATOČKA, 1991, p. 359).

Toda a dificuldade está em compreender a significação exata dessa relação estrutural universal entre a visada no vazio e o preenchimento. Segundo Patočka, o limite fundamental da fenomenologia husserliana, no qual se manifesta seu subjetivismo não superado, provém do fato de que "essa oposição é amalgamada com aquela que se dá entre a doação deficiente e a intuição" (PATOČKA, 1988, p. 243). Na medida em que, aos olhos de Husserl, só há doação em carne e osso (Leibhaft), só há presença se intuitiva, o vazio intuitivo só pode significar uma falta de presença, e de modo algum uma modalidade da presença, de tal modo que aquilo que não é dado intuitivamente só pode existir sob a modalidade subjetiva do ato. Para Husserl, o vazio não é uma modalidade, mas realmente uma negação da presença e, em conseqüência, a marca do subjetivo. Digamos de imediato que o passo decisivo dado por Patočka, e do qual depende sua concepção da relação entre percepção e linguagem, consiste precisamente em dissociar originariedade (ou doação em carne e osso) e intuitividade, e em reconhecer, por conseguinte, que uma falta $n a$ doação não é uma falta de doação: há graus no preenchimento ou na intuitividade que não comprometem a originariedade, isto é, que permanecem modalidades da presença. Trata-se, portanto, de compreender a razão da identificação sustentada por Husserl entre a originariedade e a intuitividade. Segundo Patočka, o limite da fenomenologia husserliana consiste naquilo que poderíamos chamar sua infidelidade a si mesma, à sua intuição fundamental. Essa intuição fundamental é a descoberta do campo fenomenal, da fenomenalidade enquanto tal, tornada possível pela epoché fenomenológica. O campo fenomenal é transcendente - o fenômeno é fenômeno do mundo - e, no entanto, é subjetivo pelo fato de que a tese de existência da atitude natural foi neutralizada e de que, por isso mesmo, o fenômeno se revelou relativo, em sua transcendência mesma, à consciência intencional. Ora, Husserl não consegue respeitar a autonomia, isto é, a transcendência da esfera fenomenal e, em conseqüência, 
acaba por escorá-la em algo real, a saber, na consciência e em seus vividos imanentes. Em outras palavras, ao invés de ater-se à epoché como liberação do mundo em sua fenomenalidade, Husserl compreende-a como redução, isto é, como recondução a uma região singular, a região consciência, na qual e pela qual o campo fenomenal será então constituído. Como diz Patočka, essa realidade inicialmente modesta que é a consciência faz então uma carreira formidável: ao passo que era apenas um ente do mundo, torna-se a substância da própria constituição do mundo, numa palavra, consciência transcendental. Assiste-se então a uma cisão entre o fenomenal e o subjetivo, sob a forma da distinção entre o constituinte e o constituído: “ao passo que 'subjetivo' era inicialmente tomado no sentido da linguagem corrente, designando o fenomenal (e, nesse sentido, 'objetivo') que leva em consideração as perspectivas, os modos de doação (...), o subjetivo como vivido é agora distinguido do fenomenal que aparece no vivido" (PATOčKA, 1988, p. 207). Subjetivo não é mais sinônimo de fenomenal: tornou-se o predicado de um ente de um tipo singular, a saber, o vivido. Esse deslocamento fundamental deriva, segundo Patocka, de um cartesianismo não superado, herdado de Brentano, cartesianismo que pode ser resumido no prejuízo fundamental da doação absoluta das cogitationes (PATOčKA, 1988, p. 192), isto é, na idéia do vivido como dado a si mesmo na imanência: "O mais pesado dos fardos que a definição brentaniana dos fenômenos psíquicos faz pesar sobre o desenvolvimento ulterior do problema é a qualidade atribuída ao ato psíquico de ser interiormente dado a si mesmo" (PATOČKA, 1988, p. 232). Mas é de fato a Descartes que se deve fazer remontar esse prejuízo, fatal a toda tentativa de compreensão do campo fenomenal. A descoberta cartesiana da cogitatio, do pensamento, não é senão a do campo fenomenal, aquilo em que e graças a que o aparecente aparece. Mas, “em razão de sua orientação pela distinção tradicional essentia-existentia, Descartes faz da cogitatio um atributo essencial da coisa que sou, um atributo que, possuindo um caráter de certeza indubitável, é, ele próprio, coisal, isto é, constatável, presente-dado, objetivo. A cogitatio só é possível porque o sum é a existentia de uma substantia cogitans, o ego sendo pensado no modo do substrato, tendo o cogito como atributo essencial" (PATOČKA, 1988, p. 196). Assim, no próprio Descartes, o campo fenomenal torna-se um atributo do sujeito. 
Se Husserl não consegue respeitar a autonomia da esfera fenomenal, como lugar e modalidade da aparição do ente, é porque a doação imanente dos vividos, ela própria correlativa de uma forma de substancialismo, é compreendida como o modo originário e exemplar de doação ao qual toda aparição deve ser remetida em última análise. Em outras palavras, o caráter apodítico do sum é implicitamente compreendido como fundado na adequação que caracteriza a relação do pensamento consigo mesmo, como se só houvesse certeza de minha existência como conhecimento transparente do pensamento do qual ela é existência. Desde então, a incontestável relatividade do campo fenomenal à minha existência só pode significar, aos olhos de Husserl, o pertencimento desse campo à consciência sob a forma de vividos. Compreende-se melhor a acusação de sensualismo latente lançada contra Husserl, pois esse sensualismo não é mais que a outra face de seu subjetivismo. Com efeito, a conseqüência ou a expressão dessa cisão entre o fenomenal e o subjetivo é a distinção efetuada por Husserl entre os data hyléticos imanentes, vividos e não percebidos (o vermelho enquanto vivido e não enquanto espacial), e os momentos noemáticos correspondentes (o vermelho enquanto aspecto do objeto transcendente, isto é, enquanto espacial), correlativos da animação da hylè pela noese. O momento hylético corresponde justamente à necessidade de escorar a presença do objeto transcendente em "algo real", isto é, num ente adequadamente dado a si mesmo. O sensualismo latente de Husserl remete ao fato de que o objeto transcendente, enquanto presente em carne e osso, só pode ser constituído em vividos imanentes hyléticos, numa palavra, ao fato de que o núcleo da presença é a intuitividade compreendida como doação absoluta ou adequada do vivido sensível. A conseqüência disso é que aquilo que escapa a esse modo originário de doação, aquilo que não é preenchido por vividos sensíveis, não pode pretender a presença plena. Aquilo que, no objeto, não está presente no modo sensível, como face noemática de um momento hylético, estará pura e simplesmente ausente e, portanto, só terá direito ao modo de existência, propriamente subjetivo, do visado: “À elucidação da 'face subjetiva' dos atos caberia trazer estruturas que, não podendo apoiar-se numa pré-doação 'intuitiva', têm não obstante necessidade de um 'apoio', sendo desprovidas de significação 'objetiva' no sentido propriamente real; nada representam no seio do espaço-tempo real e tampouco 
pretendem existir elas próprias nesse quadro. O não-intuitivo, o modo 'impróprio', 'deficiente' de doação figura aqui como marca do subjetivo”" (PATOčKA, 1988, p. 203).

A abordagem específica de Patocka, que qualifica sua fenomenologia como assubjetiva, não consiste em negar a subjetividade, à qual o campo fenomenal é necessariamente relativo, mas em contestar essa interiorização da fenomenalidade sob a forma de vividos imanentes animados por apreensões, numa palavra, em recusar o momento constitutivo da fenomenologia husserliana. De fato, ao assim proceder, Husserl permanece prisioneiro da atitude natural, que doravante deve ser compreendida num sentido mais profundo, a saber, como subordinação da estrutura do aparecer a um aparecente. Se Husserl percebe a necessidade de desenlear a fenomenologia da posição ingênua de um existente transcendente, não vê no entanto que o que vale para o transcendente vale igualmente para o imanente e que há, portanto, "um ser do fenômeno como tal, que não pode ser reduzido a nenhum ente que aparece em seu seio e que, portanto, não pode ser explicado a partir do ente, quer este último seja de espécie naturalmente objetiva, quer egologicamente subjetiva" (PATOčKA, 1988, p. 239). É para essa fenomenalidade do fenômeno que a fenomenologia de Patočka nos reconduz, por assim dizer a contrapelo do movimento redutivo-constitutivo husserliano, graças a uma epoché universalizada, que suspende não apenas a tese do mundo, mas também a do ego. O caráter imediato da doação do ego deve ser considerado como um prejuízo; o aparecer para si ou de si tem, ele próprio, um a priori: remete, como todo ente aparecente, à legalidade própria do aparecer. Vê-se a conseqüência dessa epoché radicalizada: a impossibilidade de escorar a presença transcendente em um momento material imanente, enfim, a ilegitimidade da distinção entre dado hylético e noema. O momento sensível é sempre já aspecto da coisa, o preenchimento sensível existe no mesmo plano que o objeto que ele deveria apresentar. Assim, escreve Patocka, tomando o exemplo de uma caixa vermelha, "Caberia realmente analisar essa cor em dois vermelhos diferentes, distinguir entre a impressão do vermelho, de um lado, e sua apercepção objetiva como coloração da caixa, de outro? Ou então seria o vermelho da caixa ora um mediador objetivo que se retira como tal para o segundo plano, ora um objeto que se lança para frente enquanto autônomo? Onde é que se 
poderia ver nisso algo que se assemelhe à 'animação' de uma estrutura de dados? Os dois modos de doação podem estar ligados por relações de fundação recíproca, mas, nesse caso, é porque são ambos objetivos" (PATOČKA, 1988, p. 204). A conseqüência dessa exteriorização daquilo que Husserl confinava na esfera da imanência é uma espécie de embaralhamento entre o que é sensível e o que não é, ambos pertencendo ao que é presente, isto é, ao transcendente, que Patočka chama "objetivo". A diferença entre o intuitivo e o não-intuitivo, que remetia em última análise à diferença entre momento sensível imanente e ato doador de sentido, torna-se subordinada à unidade do campo fenomenal, à plena exterioridade na qual o objeto aparece. A originariedade ou a presença "em pessoa" é mais profunda que a partilha entre o vazio e o pleno, entre o inintuitivo e o intuitivo, que na verdade são apenas momentos daquela. Patočka afirma-o claramente: "se aprofundamos a teoria dos modos de doação, não há como não se tornar evidente que o 'não-intuitivo' que aparece em um modo deficiente de doação é ele próprio um ser, um ser que não é de natureza subjetiva-egológica" (PATOČKA, 1988, p. 203). Na verdade, se o não-intuitivo, o "vazio" não fosse já um modo de doação, se o ato que dá apenas a significação não remetesse na verdade a uma presença em carne e osso, toda síntese de identificação se tornaria incompreensível. É só na medida em que o objeto que me aparece atualmente numa presença sensível já me foi dado no modo deficiente que posso reconhecer um objeto, que posso, por exemplo, ser posto em presença daquilo de que falo. A fim de que o recobrimento constitutivo do reconhecimento seja pensável, é preciso, de um modo ou de outro, que a visada no vazio e o preenchimento se situem no mesmo plano, que a visada no vazio seja, portanto, um dado no vazio, enfim, que seja o mesmo objeto que se mostre, ora no modo deficiente, ora no modo de auto-doação (PATOČKA, 1988, p. 203). Assim, “a presença em pessoa por assim dizer qualitativa, o dado das próprias singularidades do ente singular na plenitude das cores, etc., não é a presença em pessoa em geral. Que o lado de trás desta mesa não esteja presente em pessoa, isso não significa que não esteja presente em pessoa o fato de que a mesa enquanto objeto físico tem necessariamente um lado de trás" (PATOčKA, 1995, p. 178). Em outras palavras, não é porque estou em condições de apreender sempre novos aspectos do objeto que eu sei que ele está aí; é, pelo contrário, na 
medida em que o apreendo de saída como aí que sei que posso explicitar indefinidamente seus aspectos. Ora, essa doação do "aí” que garante minha percepção do objeto, doação, por assim dizer, de sua perceptibilidade, não se torna menos originária pelo fato de ser por princípio deficiente na medida em que chama por um preenchimento. De um modo mais geral, cabe reconhecer que há uma doação originária não-intuitiva do mundo (e isso, por princípio, uma vez que o mundo é uma totalidade não totalizável) que é a condição de possibilidade de todo preenchimento intuitivo. Essa doação de modo algum pode ser remetida a um ato subjetivo que vem conferir um sentido: trata-se, pelo contrário, daquilo que há de mais “objetivo" ou transcendente, daquilo que é da ordem da pura presença. Cabe, portanto, reconhecer um dado originário mais profundo que a distinção entre a antecipação e o preenchimento, entre a intenção e a intuição: "que eu sempre tenha novamente, onde quer que me encontre, a possibilidade de realizar a mesma continuação, isso não é simplesmente antecipado, mas dado, não sob a forma de uma simples intenção, mas de uma presença independente do preenchimento contingente ou da simples antecipação" (PATOčKA, 1995, p. 178). Assim, aquilo que em Husserl era da alçada do ato (da intenção, diz Patocka) deve ser revertido para a conta do fenomenal, isto é, do transcendente: as "intenções" pertencem àquilo com que o sujeito se defronta, são as "linhas de força” do aparecer no seio do aparecente (PATOČKA, 1995, p. 172).

No entanto, pensando bem, uma tal conclusão não está muito distante daquilo que está implicado numa consideração rigorosa da noção de visada no vazio. Com efeito, se a visada signitiva não é preenchida pelo ato que dá o objeto, pelo ato intuitivo, nem por isso é uma simples representação do objeto: ele entra em relação com o objeto ele próprio. Ora, isto só é compreensível sob a condição de reconhecer que esta visada põe em presença do objeto, ainda que num modo diferente, no modo do vazio. $\mathrm{O}$ objeto não se ausenta da visada: apresenta-se para ela como ausente. Assim, levada a suas últimas conseqüências, tal posição implica realmente reconhecer que o vazio é já um modo de presença e que a visada no vazio, recaindo sobre o próprio objeto, se abole enquanto simples visada; precede-se a si mesma, por assim dizer, no seio do objeto, vem recolher, na verdade, um ser já aí do objeto, portanto uma presença cuja deficiência e cujo chamado por um preenchimento não contradizem a origina- 
riedade. É o que o próprio Patočka reconhece pelo menos uma vez. Ao interrogar-se acerca da "consciência de significação" sem ilustração intuitiva, conclui que "o próprio Husserl acaba por reconhecer que mesmo nesse caso há aí, isto é, diante de nós, mais que os sons proferidos, o sinal gráfico, etc. Ora, esse 'mais' nada tem de subjetivo. É a própria coisa que está aí, num modo deficiente de doação” (PATOčKA, 1988, p. 236).

Seja lá como for, trazendo à luz no modo crítico as raízes do sensualismo latente que compromete a teoria husserliana da doação, Patočka dá um passo decisivo, que talvez não seja mais que um modo de restituir à descrição husserliana sua própria coerência. Na medida em que há uma presença aí em frente, no seio do fenomenal, daquilo que não é preenchido no modo sensível, mas apenas significado, é preciso dissociar originariedade ou doação em carne e osso e intuitividade, e ultrapassar a alternativa simples entre o vazio e o pleno, como alternativa entre a falta e a plenitude, em proveito de uma originariedade que comporta ela própria graus. Isso significa que o intuitivo puro ou o signitivo puro são abstrações, pois o pleno é contaminado, por assim dizer, pelo vazio no qual se destaca, e o vazio é já um modo de presença enquanto suscetível de ser preenchido: a presença em carne e osso implica sempre um certo grau de intuitividade, mas também uma dimensão de inintuitividade. Como escreve Patocka, "o mundo é originariamente dado, mas nem tudo nele é dado da mesma maneira. A originariedade não é uma marca unitária, ao contrário, comporta gradações e qualidades diversas. Assim, aquilo que é dado enquanto qualitativamente presente é originariamente dado num outro sentido que aquilo que, na conexão do mesmo ente, é dado como vazio, de modo não qualitativo; o vazio não é de modo algum uma não-doação, mas um modo de doação" (PATOčKA, 1995, p. 176). Tal conclusão corresponde, na verdade, a uma verdadeira subversão da perspectiva husserliana. De fato, como o indica a escolha dos termos, Husserl pensa a visada signitiva de modo negativo, como falta com relação à doação intuitiva sensível (perceptiva), que aparece então como o verdadeiro telos da doação. $\mathrm{O}$ vazio é a negação do pleno, a falta no preenchimento qualitativo, uma falta de presença. Em Patocka, pelo contrário, em razão do caráter gradual da doação do mundo, que não pode, como tal, estar presente em pessoa, a presença intuitiva aparece antes como a extremidade de uma doação que é essencialmente defi- 
ciente ou vazia, ainda que em graus diversos. O intuitivo é pensado como uma modalidade do originário que comporta necessariamente a inintuitividade: precisamente como seu grau último ou superior, ali onde o mundo se cristaliza em presença sensível. Enfim, contrariamente ao que ocorre em Husserl, pode-se dizer que o pleno é uma modalidade, decerto privilegiada, do vazio, e o intuitivo, uma modalidade do signitivo: não se tem uma intuição que venha preencher uma visada no vazio, mas uma visada no vazio que remete a uma presença deficiente que pode realizarse como intuição. Não há melhor maneira de dizer que há co-originariedade entre a percepção e a linguagem, que se trata de duas modalidades, necessariamente entrelaçadas, de uma mesma presença. Não é o visto que vem nos pôr em presença do dito, mas sim o próprio mundo que se apresenta a nós ao mesmo tempo no visto e no dito: "o mundo é efetivamente aquilo que vejo, aquilo que escuto... mas também, é claro, aquilo que eu penso, aquilo de que falo, etc. Os modos deficientes não são um mero nada, a presença não preenchida não é ausência" (PATOČKA, 1995 , p. 255). Cabe tomá-lo ao pé da letra. Isso não significa que estou em condições de falar de um mundo que por outro lado me seria dado numa intuição, numa palavra, que estou em condições de entrar em relações com ele no vazio. O mundo é aquilo de que falo na medida em que, na fala, é sua própria presença, e não algum signo dele, que me é dada. A fala é uma modalidade de aparecer do mundo, ao mesmo título que o ver ou o escutar, e a linguagem não é, portanto, um "patamar superior" de nossa vida que remeteria à camada mais profunda do perceptivo.

Nos fragmentos que citamos de início, Patočka vai no entanto mais longe, uma vez que afirma que o campo primário do mundo é o da linguagem, que, por conseguinte, todo modo de desvelamento se desdobra contra o fundo de uma linguagem originária, de modo que esta se torna condição de possibilidade da própria percepção. Na verdade, por radical que pareça, tal afirmação deriva daquilo que acabamos de evidenciar. Falamos de co-originariedade da percepção e da linguagem para indicar que a linguagem não se esgota num ato subjetivo que viria ser recoberto, isto é, preenchido por um ato intuitivo, para indicar, portanto, que ela põe em presença do objeto, exatamente como a percepção. Mas tal conclusão tinha, sobretudo, uma significação negativa: visava rechaçar 
a idéia do caráter derivado da camada lingüística. Com efeito, como já o sugerimos, não é inteiramente correto falar de co-originariedade na medida em que, se percepção e linguagem são ambos da ordem da originariedade, há não obstante como que um primado do modo deficiente sobre o modo intuitivo. É verdade que a presença intuitiva, o preenchimento qualitativo realmente aparece como um cumprimento do que só está presente no modo deficiente. Mas, justamente, a intuição vem sempre preencher ou especificar o que de início só se dá no modo não-intuitivo. O preenchimento só tem sentido contra o fundo de um vazio, que já não é mais o da subjetividade, mas o da presença deficiente na medida em que esta não é um mero nada: enfim, a intuição, a presença qualitativamente preenchida advém realmente contra o fundo de um mundo, isto é, de uma presença que, por essência, não pode ser apresentada em sua plenitude, que necessariamente faz falta. A lei do aparecer é a de que toda aparição se destaca contra o fundo de um mundo e é co-aparição do mundo como totalidade inaparecente (PATOČKA, 1995, pp. 177, 211); é por isso que nenhuma aparição atinge realmente a plenitude: permanece sempre escavada ou aspirada pelo vazio do mundo do qual se separa. $\mathrm{O}$ pertencimento ao mundo, que implica uma co-aparição do mundo, constitui a própria forma da experiência; nenhum ente singular pode aparecer sem que apareça em pessoa o mundo como aquilo que, no entanto, necessariamente faz falta ${ }^{1}$, e é por isso que "coisa alguma, estado algum pode aparecer sem estar incluído nos campos intuitivo-não intuitivo, vazio-plenitude, proximidade-akmé-distância" (PATOČKA, 1995, p. 198). Como vimos acima, a condição de toda percepção é que me seja dada a possibilidade de continuar a experiência, isto é, a cena originária ou o espaço de jogo no seio do qual se desdobram todos os preenchimentos, na forma de uma presença "independente do preenchimento contingente ou da simples antecipação vazia”. O que equivale a dizer que no seio dessa co-originariedade há graus e, em suma, um momento que é mais originário que o outro na medida em que é condição dele, a saber, essa presença não preenchida que funciona como a moldura de toda intuição. A falta na doação que caracteriza a cena do mundo, totalidade universal intotalizável, não é uma falta de doação, isto é, mera ausência, mas sim a própria condição de toda doação, o próprio solo da presença. Aquilo a que a linguagem remete, aquilo que não está intuitivamente 
dado, mas apenas visado em sua ausência mesma, aparece como a condição de possibilidade da própria percepção. Se o mundo é de fato aquilo que, em razão de sua infinidade, só pode ser dito e nunca apresentado, cabe reconhecer que aquilo que aparece na percepção é tributário daquilo que é alcançado na linguagem.

Não obstante, isso ainda não justifica a afirmação de que a linguagem seja a condição de possibilidade da percepção. Com efeito, mostramos que toda doação intuitiva remete a um modo de presença não intuitivo, que não é senão o do mundo. Mas, justamente, isso equivale a afirmar que o que Husserl apreendia em pleno coração dos atos de expressão remete, na realidade, a um modo originário de presença que, muito embora decerto fundamente a possibilidade da linguagem, não se esgota nesta última. $\mathrm{O}$ modo de presença que convém àquilo que permanece por preencher não é o das palavras, mas sim o do mundo. Nesse sentido, Patočka priva a fala da posição que Husserl lhe conferia, uma vez que esta não é mais que um modo, entre outros, de remissão à presença originária do mundo e a significação, na medida em que remete sempre a um aspecto do mundo, não precisa mais da vida das palavras. Nem por isso é menos verdade que Patočka distingue entre essa fala, à qual o sentido não deve mais muita coisa, e uma linguagem originária que constitui a condição de possibilidade da própria percepção. Ora, que sentido pode haver em uma linguagem que já não coincide mais com a fala propriamente dita? Em que sentido a linguagem pode estar na raiz da percepção? Na medida em que, como o vimos, toda intuição se destaca contra uma cena que é originariamente dada de um modo não sensível, a linguagem só poderia constituir a condição de possibilidade da percepção na hipótese de estar implicada na própria abertura dessa cena, isto é, na hipótese de caracterizar o modo de doação específico do ente percebido na medida em que este surge sempre contra o fundo de um Espaço mundano não intuitivo.

É justamente nessa direção que se embrenha Patocka, num texto redigido por volta de 1960, intitulado "O espaço e sua problemática". A questão que ali se coloca é a da constituição do espaço na medida em que essa constituição remete a uma relação que não é ela própria espacial. Trata-se, portanto, de trazer à luz o modo de relação originária que subjaz às relações propriamente espaciais como relações de proximidade e de distância, relações que comandam por sua vez a estrutura de pertenci- 
mento. A constituição do espaço é constituição de um "dentro" que é desdobrado por uma relação de proximidade: a proximidade não é proximidade no espaço, é antes o espaço que vem a ser aberto pela proximidade como o "entre" ou o "dentro" que ela circunscreve. As coisas não são próximas na medida em que estão no espaço; pelo contrário, estão no espaço porque são próximas. O espaço deve, desde então, ser constituído numa relação de proximidade que, por assim dizer, o precede. É justamente sob o modo da linguagem, como relação originária de interpelação, que Patočka pensa essa proximidade constitutiva e é por isso que ele constitui o espaço a partir da relação que está implicada nos pronomes pessoais: "A proto-estrutura $e u$-tu-isso é um traço originário de todo 'dentro', aquilo que sempre já nos é familiar no desenrolar de toda e qualquer experiência: a forma primordial de toda experiência. O pronome pessoal não é algo derivado, que substitui os nomes (e as coisas). Pelo contrário, é mais originário que todos os nomes e todas as coisas. A lei do pronome pessoal é a lei primordial da experiência que se revela assim interpelação; a interpelação não é uma simples metáfora, mas a própria essência da experiência" (PATOčKA, 1988, p. 61)2. Trata-se efetivamente aqui da condição de possibilidade da experiência, isto é, dessa cena ou desse espaço de jogo originário, no qual, como vimos, toda aparição tem lugar. A proximidade que abre esse espaço é a do $t u$, e o tu é fundamentalmente aquele que me interpela: a relação originária que abre a própria espacialidade do espaço é interpelação. Nesse sentido, precisa Patocka, o eu é tributário do $t u$, pois só se constitui como tal na medida em que é interpelado por ele: situo-me, entro no mundo na medida em que um tu me interpela. Não obstante, cabe também precisar que o $t u$ não é necessariamente um outro $e u$, mas sim, de modo mais preciso, aquilo que me interpela, aquilo que me fala e que, portanto, pode ser um ente qualquer. Assim, o espaço no qual o ente pode aparecer é constituído por uma relação de proximidade, isto é, uma relação na qual advém algo próximo, e essa relação deve, ela própria, ser compreendida como linguagem, no sentido não metafórico da demanda ou do chamado. Como Patočka dirá alhures, as coisas falam comigo, "têm algo a me dizer" (PATOČKA, 1988, p. 246) e o sujeito deve ele próprio ser caracterizado como resposta a um chamado fenomenal (PATOčKA, 1988, p. 245). O surgimento do espaço é o surgimento da proximidade e o próxi- 
mo é aquilo que fala comigo: nesse sentido, a linguagem, compreendida como um endereçar-se e não mais como fala, é efetivamente a condição mesma da percepção. É o que Patočka precisa ao especificar a relação entre o sensível e a proximidade: "A oposição proximidade-distanciamento, fundada no 'dentro' originário, tem uma significação que ultrapassa os limites do sensível. Há também uma proximidade mais originária que se manifesta muito claramente ali onde sentimos a presença de uma coisa 'ausente' a despeito de todos nossos esforços para afastá-la e nos livrarmos dela, ou então, caso se trate de uma coisa desejada, a despeito de todos os obstáculos que se opõem à presença sensível. Banida da proximidade sensível, permanece na proximidade mais originária. $\mathrm{O}$ 'dentro' originário não é uma simples função do mundo sensível. Pelo contrário, o sensível como tal é apenas uma das estruturas desse 'dentro"' (PATOČKA, 1988, p. 64). Não se poderia enunciar melhor o fato de que a proximidade que se constitui na interpelação, longe de repousar na presença sensível, funda, pelo contrário, esta última. Se o próximo, isto é, o que há para mim, o que aparece no mundo (e, na verdade, faz o mundo aparecer) é aquilo que me interpela, então o ausente desejado, em direção ao qual posso me orientar e ao qual posso me endereçar a despeito da distância geométrica, é mais próximo que um ente sensível que não é um $t u$ por não me interpelar. Assim, o sensível é realmente uma modalidade entre outras da proximidade, isto é, da originariedade: não é porque uma coisa é sensível que ela é próxima; é, pelo contrário, na medida em que é próxima que pode tornar-se sensível. O sensível é realmente uma especificação da proximidade, isto é, daquilo que me interpela, e a intuição, uma modalidade da presença originária não intuitiva, que é a do chamado. Chegou efetivamente o momento de precisar que, na interpelação, a proximidade é necessariamente o avesso de uma distância, de modo que seria ainda mais rigoroso caracterizar a experiência como aproximação ou des-afastamento (Entfernung), como já o fazia Erwin Straus. De fato, observa Patocka, "na relação entre o eu e o tu entra em compensação todo o vazio do coração que não está orientado apenas para as singularidades, mas para a totalidade, para o supra-individual, para o conteúdo omni-englobante. Entre o eu e o $t u$, há um vazio que nada poderia preencher - um vazio indispensável para o acionamento e para o jogo dessa relação originária” (PATOčKA, 1988, p. 67). O "vazio do coração” 
é uma expressão tomada de Scheler, que mostra que as formas vazias do espaço e do tempo só são possíveis em um ser cujos desejos são sempre mais insatisfeitos do que preenchidos (SCHELER, 1951, p. 60). Para o próprio Scheler, que Patočka evoca nominalmente no início do texto que comentamos, a espacialidade remete ao desejo, na medida em que este é correlativo a um chamado. Seja como for, vemos aqui que a relação $e u$ - $t u$ não poderia dessolidarizar-se do isso do qual emerge o $t u$ pela interpelação: a proximidade é sempre conquistada contra o fundo de uma distância irredutível, que não é senão a do próprio mundo como totalidade omni-englobante. É finalmente o próprio mundo que me interpela, assumindo a forma de um $t u$, que guarda algo da profundidade de onde provém, e cuja proximidade é a outra face de uma distância ou de um vazio. Na verdade, é esse vazio ou esse jogo, marca deixada no seio do tu pelo isso do qual deriva, que funda sua espacialidade e, se é fato que a constituição do espaço repousa sobre a do próximo, nem por isso é menos verdade que não há espaço sem distância. Na relação de proximidade aberta pela interpelação, essa distância é garantida pelo "vazio do coração", isto é, pelo fato de que, nessa "conversa" originária que é a experiência, aquilo que me interpela não responde ao meu próprio chamado - ao pé da letra: deixa a desejar. A distância que subsiste no seio da proximidade e permite determiná-la como proximidade propriamente espacial está fundada no próprio desejo. Enfim, dizer que só há interpelação contra um fundo de ausência é reconhecer que a percepção é realmente uma modalidade de uma presença ainda mais originária e irredutivelmente deficiente. É ao interpelar que esse fundo de presença se constitui como tu e me constitui, por isso mesmo, como eu, isto é, finalmente aparece. A interpelação designa exatamente esse preenchimento trabalhado pelo vazio, essa intuição contra um fundo de ausência que caracterizam todo aparecer e, nesse sentido, pode-se considerar a linguagem - que ainda não é fala, mas é certamente aquilo que irá fundála - como a condição mesma da percepção.

Não há como evitar, ao cabo dessa análise, um certo sentimento de insatisfação. Vê-se claramente que a linguagem não é uma camada derivada que remete a um solo perceptivo originário e se esgota inteira em atos subjetivos. Dissociando a doação em carne e osso da intuitividade, Patočka 
consegue evidenciar a co-originariedade da linguagem e da percepção na medida em que ambas remetem a modos de presença, decerto diferentes, mas igualmente primitivos. Mais ainda, a própria essência do aparecer implica a polaridade do vazio e da plenitude, do intuitivo e do não-intuitivo, de modo que há um entrelaçamento originário do sensível e do signitivo, da percepção e da linguagem. É por razões essenciais, que se vinculam ao "como" do aparecer, que o mundo é ao mesmo tempo um mundo visto e um mundo dito. Segue-se disso que a percepção propriamente dita, na medida em que supõe a doação prévia da cena do mundo, remete a um modo de doação que não pode ser perceptivo: o ser-dado da continuabilidade indefinida da experiência não é um ser-percebido. Patočka fala então em interpelação ou em chamado para qualificar isso que só se dá sob a forma de um "devendo ser preenchido": o ser desse vazio que não é um nada só pode ser o da exigência. É rigorosamente nesse sentido que Patočka evoca uma linguagem originária que seria mais profunda que a percepção e que constituiria sua condição de possibilidade.

Nossa reserva incide justamente sobre esse ponto. Não diz respeito à decisão de recorrer à linguagem para caracterizar o que se dá antes de toda fala, para descrever uma experiência que é antes caracterizada pela passividade da pura solicitação que por uma dinâmica comunicativa. De fato, nada impede de reconhecer por sob aquilo que entendemos por linguagem um modo de ser originário do qual a abertura silenciosa do mundo poderia ser uma modalidade. Talvez o Chamado designe um conceito da linguagem mais profundo que a partilha do próprio e do metafórico, conceito do qual a fala do Outro e a presença vazia do mundo poderiam então ser duas modalidades derivadas. A dificuldade reside antes no fato de que, na inversão operada por Patocka, a distinção husserliana entre percepção e linguagem vê-se preservada. No exato momento em que Patočka mostra que presença intuitiva e presença deficiente são igualmente originárias, isto é, são modalidades de um único e mesmo mundo, ele continua tematizando no modo dualista as prestações do sujeito que correspondem a essas duas dimensões entrelaçadas do aparecer, ao falar de linguagem para a doação do vazio e de percepção para a do intuitivo. A vertente "subjetiva" da descrição está manifestamente em recuo ou em atraso com relação à vertente objetiva. $\mathrm{Na}$ 
verdade, aquilo que vale para a vertente objetiva, isto é, para o mundo, deve valer igualmente para a vertente subjetiva: se o aparecer é fundamentalmente unitário, se o vazio e a plenitude são de fato duas modalidades derivadas de uma mesma presença em carne e osso, a saber, a do mundo, então cabe perguntar-se qual é o sentido de ser do sujeito enquanto correlativo à unidade do mundo, em que modalidade originária de existência se enraízam a linguagem e a percepção, enfim, onde se funda a unidade destas para além de sua dualidade. Trata-se, em outras palavras, de trazer à luz do dia um sentido de ser do sujeito que permita dar conta tanto da abertura para o vazio do mundo quanto do pôr em presença de um ente sensível, que possa ser indistintamente resposta a um chamado e visão do ente. Ora, como escreve Patocka, as coisas realmente têm algo a me dizer: "dizem-me o que devo fazer" (PATOčKA, 1988, p. 246). A resposta do eu à linguagem do mundo assume a forma do agir e Patočka precisa no texto sobre o espaço já evocado que a relação do eu com o $t u$ é "uma relação emotiva e volitiva, uma tensão no elemento da ação e das forças concretamente vividas" (PATOČKA, 1988, p. 64). Enquanto resposta ao chamado do mundo, o sujeito é fundamentalmente movimento e é enquanto tal que pode trazer o mundo à presença. $\mathrm{O}$ movimento é ao mesmo tempo resposta e intuição, relação com o mundo segundo sua profundidade e desvelamento do ente finito. É por isso que Patočka define a força que caracteriza a existência fundamentalmente como "força vidente". Assim, a co-originariedade da percepção e da linguagem, evidenciada por Patočka, reconduz a uma fenomenologia do movimento que constitui certamente sua contribuição mais original. A fenomenologia de Patočka encontra seu remate numa "teoria cinética da percepção", sobre a qual repousa a doação originária do mundo segundo a graduação do vazio e do preenchimento, e que deve permitir ultrapassar definitivamente a dualidade ainda abstrata de uma linguagem originária e de uma percepção da qual esta seria a condição.

\footnotetext{
1 "A forma-do-mundo (Weltform) da experiência é ao mesmo tempo o que torna possível uma experiência do mundo"(PP, p. 214).

2 Um pouco adiante, ele caracteriza o dentro originário como "conversa” (PATOČKA, J., 1988, p. 67).
} 


\section{Referências bibliográficas}

PATOČKA, J. 1976. Le monde naturel comme problème philosophique. La Haye: Martinus Nijhoff.

PATOČKA, J. 1995. Papiers phénoménologiques. Trad. E. Abrams, Grenoble: Millon.

PATOČKA, J. 1988. Qu’est-ce que la phénoménologie? Trad. E. Abrams, Grenoble: Millon.

PATOČKA, J. 1991. Husserls Anschauungsbegriff und das Urphänomen der Sprache, in: Ausgewählte Schriften. Stuttgart: Klett-Cotta, IV.

SCHELER, M. 1951. Die Stellung des Menschen im Kosmos. Trad. M.

Dupuy, La situation de l'homme dans le monde, Paris: Aubier. 